\title{
Patients in the coronary care unit who received remote, intercessory prayer had fewer overall adverse events, but did not have shorter hospital stays
}

Harris WS, Gowda M, Kolb JWet al. A randomized, controlled trial of the effects of remote, intercessory prayer on outcomes in patients admitted to the coronary care unit. Arch Intern Med 1999 Oct 25;159:2273-8.

QUESTION: Among patients admitted to a coronary care unit (CCU), does remote, intercessory prayer (praying for others) reduce complications and length of hospital stay?

\section{Design}

Randomised (allocation concealed), blinded (patients, clinicians, and outcome assessors), controlled trial.

\section{Setting}

A CCU in Kansas City, Missouri, USA.

\section{Patients}

1013 patients admitted to the CCU over a 12 month period. Patients admitted for work up before transplantation were excluded. Follow up was 98\% (23 patients were excluded after randomisation because they were admitted for $<1$ day).

\section{Intervention}

484 patients were allocated to intercessory prayer. A total of 75 intercessors were recruited from the community; all intercessors had to agree with the following statements: "I believe in God. I believe that $\mathrm{He}$ is personal and is concerned with individual lives. I further believe that $\mathrm{He}$ is responsive to prayers for healing made on behalf of the sick." For each patient, a team of 5 intercessors, who received no information other than the first name of the patient, was asked to pray daily for the next 28 days for "a speedy recovery with no complications" and anything else that seemed appropriate; prayer was offered individually rather than in groups. Patients were unaware that they were being prayed for. 529 patients were allocated to usual care.

\section{Main outcome measures \\ Main outcome was the clinical course of the patient's stay in the CCU, summarised using the severity adjusted Mid America Heart Institute-Cardiac Care Unit (MAHI-CCU) score (a weighted and summed score of all new diagnoses, events, or procedures occurring $\geqslant 24$ hours after admission to the CCU until discharge or death; scores ranged from 1 [need for anti-anginal agents, antibiotics, arterial monitoring, or catheterisation; development of unstable angina] to 6 [death]). Secondary outcomes included the un- weighted MAHI-CCU score (a simple count of events, procedures, and prescriptions after CCU admission) and length of CCU and hospital stay (beginning 1 day after admission to the CCU). Inter-rater agreement on the MAHI-CCU scores for 10 physicians was $96 \%$.}

\section{Main results}

Analysis was by intention to treat. Patients in the intercessory prayer group had an $11 \%$ reduction in weighted MAHI-CCU scores $(6.35 v 7.13, \mathrm{p}=0.04)$ and a $10 \%$ reduction in unweighted MAHI-CCU scores (2.7 $v 3.0, \mathrm{p}=0.04)$ compared with patients who received usual care. The groups did not differ for mean length of CGU stay (1.12 $1.23 \mathrm{~d}, \mathrm{p}=0.28)$ or mean length of hospital stay $(6.48 v 5.97, \mathrm{p}=0.41)$.

\section{Conclusions}

Among patients admitted to a coronary care unit, those who received daily remote intercessory prayer had lower cardiac care unit scores (representing fewer overall adverse events) than did patients who received usual care. Length of cardiac care unit stay and hospital stay did not differ.

\section{Source of funding: no external funding. \\ For correspondence: Dr W S Harris, Lipid Research Laboratory, Saint Luke's Hospital, 4401 Wornall Road, Kansas City, MO 64111, USA. Fax +1816932 8278 .}

\section{COMMENTARY}

Research on the interface between faith and health is an important development in the world of health research. The study by Harris $e t$ al examined the effect of remote intercessory prayer on the health outcomes of patients admitted to the CCU. Only 1 other controlled study has examined the effects of intercessory prayer in a similar group of patients, and it showed that patients who received intercessory prayer had fewer life threatening physical events and complications. ${ }^{12}$ In both studies, prayer was provided by individuals who did not know the patients and was often provided in addition to prayer by family, friends, and clergy. Rather than having others pray for patients, Ai et al studied the effect of the private prayers of patients who had coronary artery bypass grafting and found that these patients had decreased depression and general distress one year after surgery.

A major strength of this study is the avoidance of bias by blinding of patients, clinicians, and outcome assessors. The authors identified 2 concerns about the MAHI-CCU scores. Firstly, this measure was designed specifically for this study and was not evaluated for validity; and secondly, despite the finding of a statistically significant difference in scores between the 2 groups, it is difficult to know whether an 11\% reduction in MAHI-CCU scores is an important clinical difference.

Harris et al see intercessory prayer as communication with the Judeo-Christian God by those who believe in God, and believe that prayers are answered. But, as Shelly and Miller note: "prayer is not just asking for things. . it is the language of relationship, not magic or manipulation" (p.236). ${ }^{4}$ A more complete understanding of the efficacy of prayer for healing of the whole person would be gained from studies using a variety of forms (eg, specific conversational prayer for the patient's expressed needs while the patient is present or meditative prayer) and intensities of prayer. More direct, detailed, and personal forms of prayer may show greater healing effects. Outcome measures of psychological and spiritual health or wellbeing should also be assessed.

Few studies have evaluated intercessory prayer, and the authors suggest that further studies are warranted. Until further work is done, we can only suggest to CCU nurses that encouraging and supporting the daily prayer efforts of others on behalf of patients could have a positive effect on patients' physical health outcomes.

Leslie Van Dover, RN, PhD Associate Professor, School of Nursing Azusa Pacific University Azusa, California, USA

1 Byrd RC. Positive therapeutic effects of intercessory prayer in a coronary care unit population. South Med J 1988;81:826-9.

2 Roberts L, Ahmed I, Hall S. Intercessory prayer for the alleviation of ill health. (Cochrane Review, latest version 24 Nov 1998.) In: Cochrane Library. Oxford: Update Software.

3 Ai AL, Dunkle RE, Peterson C, et al. The role of private prayer in psychological recovery among midlife and aged patients following cardiac surgery. Gerontologist 1998;8:591-601.

4 Shelly JA, Miller AB. Called to care: a Christian theology of nursing. Downers Grove: InterVarsity Press, 1999. 